\title{
The Impact Of Platform On Global Video Game Sales
}

Jeffry Babb, West Texas A\&M University, USA

Neil Terry, West Texas A\&M University, USA

Kareem Dana, West Texas A\&M University, USA

\begin{abstract}
This paper examines video game sales by platform in the global market from a period spanning 2006 through 2011. As the home video game industry has rapidly matured and become established as a forefront facet of interactive entertainment in the home, we seek to determine what aspects of the video game market have the greatest impact on sales. This question is particularly poignant, as the maturation of the video game industry has witnessed efforts at both vertical integration and horizontal expansion on the part of the top game publishers and developers in hopes of solidly grounding the industry. This study employs a Kruskal-Wallis test to compare eight different gaming platforms. The results indicate Nintendo's Wii was the top selling global platform; Nintendo DS was the second tier; Xbox 360, Sony PlayStation 3, and the personal computer $(P C)$ are in the third tier; the fourth tier consists of Sony PlayStation 2 and Sony PSP; and the retired sixth generation Nintendo GameCube is the lowest sales tier.
\end{abstract}

Keywords: History of Video Games; Video Game Platform; Video Game Sales; Vertical Integration

\section{INTRODUCTION}

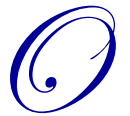

ver the past 40 years, a veritable industry has grown up around the design, development, and delivery of video games for home video game consoles and the personal computer (PC). Collectively called the "video game industry", these endeavors have greatly evolved from a cottage industry in the 1970s to a goliath that rivals the film industry for household entertainment expenditures. As the U.S. is the world's biggest video games market and manufacturer, the U.S. video game market is now worth over $\$ 20$ billion annually in software and hardware sales, which is more than four times the market size in the 1990s (Chatfield, 2010). Furthermore, video games are so entrenched in the daily lives of many people who are buying games in a variety of platforms (e.g., mobile smart phones, game consoles, PCs, etc.), are increasingly playing online (via the Internet), and are willing to pay for the privilege to do so. Blizzard Entertainment's World of Warcraft, for instance, has over 11 million player/subscribers worldwide and over $\$ 1$ billion per year in revenues. Microsoft's Xbox Live gaming service claims 20 million subscribers reaching 39 million gaming consoles and 10-million non-gaming accounts used solely for social networking benefits (Grant, 2010). Career options in the video game industry are also very healthy with 254 U.S. colleges and universities in 37 U.S. states now offering courses and degrees in computer and video game design, programming, and art (Chatfield, 2010).

Overall, a trend continues where video games are not just a fad or for the young, but increasingly an activity that incorporates nearly everyone. Sixty-eight percent of American households now play video games and many of these are online players; additionally, $43 \%$ of online U.S. game players are female. Moreover, the U.S. military spends around $\$ 6$ billion a year on virtual and simulated training programs, based around video games and virtual worlds in an offshoot of the industry dedicated to serious games (Aldrich, 2009; Reeves \& Read, 2009).

Perhaps the most remarkable aspect of the advent of the video game industry is the rapid rise of the breadth and scope of the industry itself. Even with its own humble beginnings, the movie industry was recognizable as such at an early stage. However, video games languished as a cottage industry until just the last 15 years, with the first decade of the $21^{\text {st }}$ Century witnessing meteoric gains. In fact, the budgets for developing the biggest games can now 
top $\$ 100$ million and are attracting some of the biggest names in film; many of Stephen Spielberg's, Peter Jackson's, and James Cameron's latest successes intersect appreciably with the skills sets and talents of professionals in the video game industry.

The connection to film is interesting as the determinants of box office, rental, and genre-specific sales have been of interest to academics (for example, see Litman, 1983; King, 2007; Chiou, 2008; Terry, Butler, \& De'Armond, 2005; Terry, Cooley, \& Zachary, 2010; Terry, King, \& Walker, 2010). However, it is clear that the video games industry has recently rivaled the gross revenues of the film industry and now commands budgets with rivals and exceeds that of film. A remarkable and recent feat of the video game industry transpired in 2008 when Grand Theft Auto IV took the title of the most successful entertainment release in history. Within 24 hours, Grand Theft Auto IV had grossed $\$ 310$ million, which was considerably more than the most successful book (Harry Potter \& The Deathly Hallows, at \$220 million in 24 hours) and film (Spider-Man 3 at \$117 million). Whereas it is certain that these records have been since bested, such as is the case with Modern Warfare 3 selling $\$ 775$ million in just under a week (Stuart, 2011) and Call of Duty: Black Ops 2 grossing \$1 billion in a 15-day period (Sliwinski, 2012), the success of Grand Theft Auto IV marked a milestone for an industry that now has a proper place at the table in the entertainment industry. If Grand Theft Auto IV presented a historical feat for the games industry, it did so by offering a somewhat superior entertainment experience whose level of sophistication and production values was increasingly becoming the rule for video game entertainment.

There is little debate regarding the economic impact of video games, but business (both in the practical and academic sense) has been somewhat circumspect regarding the medium. In their infancy, video games remained synonymous with puerile, crass, and shallow thrills to be obtained at the price of a quarter. The notion remains that a game may be visually titillating but will have little to offer in the way of values, insights, or craftsmanship (2010). Thus, our research interest in the determinants of video games sales represents not simply a query regarding what we can learn about what drives videos games sales, but we also wish to understand and reflect against our findings about how video games are influencing daily life. For the increasingly large percentage of the population who play them, video games represent a first-class and premiere outlet for personal and social recreation. It has been posited that the video games industry may be the most exciting and creative industry around and the evidence in support of this position is ample (Tschang, 2007; Baily, Leonardi, and Barley, 2012). A scholarly investigation of the video games industry should go beyond ballooning revenues and audiences and consider how the industry is a compendium of talents and ideas that is both influencing and cross-pollinating with film, television, and the other arts. The purpose of this research is to analyze the video game industry with a focus on comparing global sales across different gaming platforms. The organization of the manuscript consists of five sections: 1) discussion of a survey of the literature related to various aspects of gaming, 2) background information for various video game platforms, 3) a discussion of the data the model, 4) empirical results comparing the eight different gaming platforms for the years 2006-2011, and 5) concluding remarks.

\section{SURVEY OF THE LITERATURE}

There are several relevant streams of literature related to the topic of video game sales and the nature of the video games industry. First, it is important to state that the video game industry is both an entertainment and a software industry, so there are different theoretical bases that can be used to shed light on this subject. As our interest is in the determinants of video game sales, we found the literatures on networks and network effects, innovation and co-creative product development, platforms, vertical integration, and gamification to be most relevant. We discuss each area of literature to highlight the concerns and issues related to video game sales determinants in this section. The contribution of this manuscript will extend the results of Babb and Terry (2013) from a focus on North American sales to global sales revenue.

\section{Networks Ad Network Effects}

The literature on the home video game market, and industry, has been widely viewed through the theoretic lens of network effects and externalities (Binken \& Stremersch, 2009; Clements \& Ohashi, 2004; Johns, 2006; Liu, 2010; Prieger \& Hu, 2006; Shankar \& Bayus, 2003; Strube, Schade, Schmidt, \& Buxmann, 2007). The simplest understanding of network externalities, or network effects, is gained through the work of Katz and Shapiro (1985, 
1994) who state that a network effect is when a user derives additional utility from the use of a good, as the number of additional agents also consumes the good. The applicability of this body of knowledge is appropriate when it is considered that top-selling games and consoles, such as Wii Sports and Nintendo's Wii, are bolstered by positive network effects that create an information cascade (or "bandwagon") effect which increases the utility of the network as more people join, creating a positive feedback loop (Bikhchandani, Hirshleifer, \& Welch, 1992). While the earliest days of home video games may have not relied on this information cascade concept, much has changed with the advent of the Internet and the World Wide Web. Nearly every top-selling title now has some online component, which requires that players meet and face each other in interactive challenge or cooperative play. As such, the popularity of a modern video game title drives the information cascade, which further propels the success of the title. This may be among the reasons why gross revenues for home video games so far outstretch movie sales. Whereas a movie is a passive entertainment mode, the interactivity and social exchange made possible in an online game creates a lasting experience that draws others in.

The dependency that contemporary games have on communication and information networks reinforces why network effects are important and why video games support the tenets of Metcalfe's Law. Named for Robert M. Metcalfe, who invented the Ethernet standard for networks, Metcalfe's law parsimoniously states that the value of a communications network is proportional to the square of the number of its users (Briscoe, Odlyzko, \& Tilly, 2006). This ties into the contemporary video game market, as we know it, in that the market is about competing platforms rather than just the video game sales themselves. Moreover, the extent of such a network, particularly in the case of Microsoft's Xbox Live network and Sony's PlayStation network, has as much to do with the utility of a game and its resultant sales, as would be the qualities of the game. What is compelling about Metcalfe's Law is the promise of approaching exponential growth, as opposed to flat growth, which is why the axiom has gained traction with entrepreneurs, venture capitalists, and systems engineers as a quantification of the network effect. Most networked technologies and trends, such as Facebook, Twitter, and video games, require a critical mass crossover or tipping point - at which costs will be recuperated at a rapid pace. Johns (2006) finds network effects that suggests that the video games industry is no longer a niche market and should not be dismissed as such. Thus, while we are encouraged that some research has been conducted concerning this industry, we still find the video game phenomenon somewhat lacking comprehensive academic inquiry. As Poole (2000) puts it: “...video games are not going to go away. You cannot hide under the stairs. Resistance is futile. Any industry with such a vast amount of money sloshing around in it is, by that token alone, worthy of investigation."

\section{Platforms}

During the period of study (2006-2011), data show clearly that video games released for the seventh generation of home video game consoles dominate market sales. This is largely by design as hardware manufacturers, such as Microsoft, Sony, and Nintendo, have carefully developed a platform-based market where software sales subsidize relatively inexpensive hardware; that is, while the hardware's costs may be substantial, the relatively higher price point of video games allows platform owners to sell the hardware at a relatively lower price point. Economists would call this a platform-based market in that video game developers and publishers and video gamers each thrive in a market ecosystem based upon a common platform of use. Also called two-sided markets, this concept has been well articulated and explored in the economics literature (Rochet \& Tirole, 2003, 2006; Zhu \& Iansiti, 2012). The wide success of video games, and even now the mobile smart phone market, has much to do with the cultivation and control of these two-sided and platform dependent markets. In this sense, companies like Nintendo, Microsoft, Sony and Apple provide the platform upon which game developers and gamers meeting in a controlled ecosystem. Furthermore, these two-sided markets are also multi-homed in that they allow for more than one competing platform with users affiliating with more one or more such platforms. Multi-homing can be understood in other contexts; for example, when consumers carry credit cards from more than one banking network or they continue using computers based on two different operating systems (Landsman \& Stremersch, 2011). This multi-homing explains why publishers gain significant network externalities when they publish a title on multiple platforms. For instance, it is not uncommon for a gamer to purchase a title on more than one platform, such as on the PC and the Sony PlayStation 3. Multi-homing is not "free" for software developers and often the costs of maintaining a software development "code base" for multiple platforms is high; sometimes requiring the maintenance of entirely separate development teams. This is not a new problem and has been experienced in the personal computing market and smart phone industries for years. As such, multi-homing also affects the user such 
that higher multi-homing costs reduce user willingness to maintain affiliation with competing networks that provide similar services, such as between the iPhone and Android, or between the Xbox and PlayStation.

Two-sided and platform-based markets also induce new coordination behaviors between producers of goods for the platform and the consumers for goods on the platform, as moderated by the platform keeper. Additionally, the producers and consumers in this two-sided market are also subject to the coercive control exerted by the platform owner (Parker \& Alstyne, 2005). Platform owners, like Microsoft, Sony, and Apple, often charge both producers and consumers for the right to access the platform; these charges are in the form of retail pricing, subscriptions, and licensing. However, since this two-sided market increases network effects for both producers and consumers, each will exert against the network to optimize for their own needs. A solution may exist whereby only the keeper of the platform may alter portions of the demand curve to make the platform-dependent market work. This explains why the platform providers and gate-keepers (e.g., Microsoft and Sony in the case of video games) will subsidize the price-sensitive aspect of the platform market - the platform itself. Just as Adobe eventually made their reader free and then commanded a healthy sum for the writer portion of their software, the gaming industry charges very full prices for games but keeps the hardware prices low (Parker \& Alstyne, 2005; Trispas, 2000). Whereas the PC is an open platform and open to the vagaries of multiple vendors and software piracy (Bhattacharjee, Gopal, \& Sanders, 2003), gaming platforms are very locked down and extensively controlled (Parker \& Alstyne, 2005). The distinction of the PC is important as this platform is regaining its status, as evidenced in the data in this paper, as massively-online games, such that many PC games exploring the 'freemium' model toward revenue accrual are gaining in popularity (Hsu, P. and Tsai C., 2012).

\section{Co-Creation and Product Development Innovation}

What is also experienced in these emerging two-sided and platform-based markets are new collaborative and cooperative behaviors between producers of goods for the platform and the consumers for goods on the platform. This is especially evident in the degree to which producers increasingly rely on consumers for product development and innovation (Arakji \& Lang, 2007). Developers utilize focus groups, open discussion forums, and extensive public beta testing periods in order to collaborate with consumers in an unprecedented manner. In fact, it is increasingly customary to charge for "early access" to games that are not yet finished (Orland, 2013). Additionally, online funding sources, such as kickstarter.com, encourage gamers to "invest" in the game prior to or in parallel to its development (Wortley, 2013). These emerging relationships are more predominant on the PC vs. the seventh generation console platforms. In any case, this relationship between game developers and game consumers strengthens the two-sided market and keeps the platform as a central concern; even in the case of the PC. Moreover, many producers and consumers of video games become locked in a long-term innovative relationship as seen by subscription-based game services, such as World of Warcraft and EVE Online (Gallagher \& Park, 2002; Jones, Svejenova, \& Srandgaard, 2011). Even as 'freemium' models are emerging in alternative to subscriptions, the innovative relationship persists such that gamers are certainly a factor in steering and shaping the character of the service (Wang and Chin, 2011). Thus, we see in the two-sided gaming market a high degree of what Prahalad and Ramaswamy (2003) describe as the "co-creation of value". Gamers get the features and game mechanics they crave and producers get loyalty to the product, the brand, and the platform (Binken \& Stremersch, 2009; Liu, 2010; Williams, 2002). The importance of this co-creative relationship is in the phronetic learning afforded to both the producer and consumer. This learning is conducted very close to real-time and allows the two-sided market to adjust very quickly. This phronetic relationship is very conducive to the natural developmental disposition of the video game industry, which is very creative and innovative (Zackariasson, Styhre, \& Wilson, 2006).

\section{Vertical Integration}

Another aspect of video game sales is the degree to which vertical integration has been used. This is most clearly seen when the platform producers also develop the content for the platform (Claussen, 2011; Gil \& Warzynski, 2010). Halo is a top-selling video game franchise which has capitalized on this phenomenon. At one point, Microsoft-owned Bungie, Inc. - the development studio that makes the game, as well as the Xbox - the platform targeted by the game, and Xbox Live - the player network required to utilize the game in a multiplayer scenario. This vertical integration does not work in all cases, but each video game console maker engages in some degree of vertical integration. This integration is also very evident in the Wii Sports title. The sales data from the 
study period (2006-2011) shows that Wii Sports is the best-selling title. However, when we consider that this title is bundled with the hardware platform, it is clear that vertical integration is somewhat responsible for the sales performance as the title is coupled to the hardware.

\section{Gamification}

While there are many market mechanics governing home video game sales, it is important to stress that the demographics in many developed (and some developing) economies suggest that video games are now fairly entrenched as a part of daily life (Johns, 2006; Williams, 2002). As such, the structures of interaction inherent in gaming are becoming ubiquitous (Reeves \& Read, 2009). To wit - people collect coupons via web services, such as Groupon, they earn points for being loyal customers of airlines and grocery markets, and they compete to unlock badges as a signification of accomplishment in Foursquare. As the mechanics and structures of video gaming are increasingly applied as a customer relations scheme in non-gaming settings, the two-sided and platform-oriented video game market is very effective at reinforcing the importance of gaming in daily life. This means that household spending is more likely to accommodate home video games in the entertainment budget, to the possible exclusion of other media. While empirical studies of this emerging phenomenon are presently lacking, this concept is gaining traction in the marketing and management literatures (Benthem, 2011; Deterding, Khaled, Nacke, \& Dixon, 2011; Deterding, Sicart, Nacke, O'Har, \& Dixona, 2011). Gamification has the potential to further impact video games sales as the mechanics of gaming present in non-gaming activities may, through marketing, attract more players to a game. We can see this in casual games made successful via Facebook from the games publisher Zynga, such as Farmville and Mafia Wars, or with Angry Birds from games publisher Rovio. It is clear that these game elements, approached from the more casual and "fun" side, may draw more consumers into the game market. Concomitantly, a "serious games" sub-market has opened up such that government agencies and militaries use aspects of game mechanics to develop simulations to explore problem spaces in virtual realities (Aldrich, 2009). Like casual games, serious games also potentially draw in more participants as personal editions of the simulation software are made available. Two examples of this is the personal edition of Steel Beasts Professional from eSim Games (a games developer) and the link between Virtual Battle Space (the professional simulator) and Armed Assault (the entertainment title) from Bohemia Interactive (also a games developer). With these two examples, we can see how a company involves itself in both the serious games market and the entertainment market simultaneously.

\section{DESCRIBING THE PRINCIPLE HOME VIDEO GAME PLATFORMS}

This study uses video game sales data, typically aggregated and reported by entities such as the NPD Group and VGChartz, from the period dominated by the seventh generation of video game consoles and platforms (20062011). A brief perusal of this data reinforces the fact that video game consoles are the medium and mode of choice in terms of what sells in the video game market. For instance, in the last five years in North America, only a handful of personal computer titles have been present in the sales charts and none of these titles broke the top 10 (VGChartz, 2011). However, outside of North America, the PC retains some degree of equal presence. It is possible that in the future, the dominance of the console will ease in favor of a multiplicity of platforms. However, in order to understand the dominance of video game consoles during the study period, we now explore the characteristics and nature of the common and prominent video game consoles. First, we offer a brief history of video games in order to establish the predecessors to the current generation of video game consoles and to establish why video game consoles are the dominant technology platform driving video game sales.

\section{A Brief History of Video Games}

In the earliest days, video games were nothing more than curiosities on oscilloscopes and other primitive monochrome displays. The pre-cursors to today's video games centered on either text-based adventure games or simple games such as the 1972 release of Pong (Novak, 2008). In many cases, these games were simply novelties and amusements with no thought of commercialization or widespread distribution (Anderson, 1983). Into the 1950s and 1960s, the use of computers for games remained a mostly mainframe-oriented activity at the universities which housed these mainframe computers (Graetz, 1981). Toward the latter portion of this period, a milestone in modern computing, the arrival of UNIX, was also the progenitor of several games, including Space Travel, which was 
among the principle obsessions for the designers of that operating system (Ritchie, 2011). As transistors proliferated and as the hardware needed to show video images to cathode ray tubes became less expensive, the earliest arcade game machines arrived in the 1970s. This period spawned three important developments in video game history: 1) the maturation and proliferation of coin-operated video game arcade machines, 2) the earliest video game consoles for home use, and, 3) the earliest personal computers for home use. Thus, from the earliest days, home video game console systems were available simultaneously with home computers. However, the PC was usually more expensive than the console, which remains generally true to this day. Also during the 1970s, as multi-user UNIX systems continued to proliferate amongst businesses, universities, and government agencies, mainframe games continued to develop. There were largely text-based adventure games such as Star Trek, Adventure, Zork, and, in general, Multi-User Dungeons.

While video games continued to flourish on personal computers, arcade video games waned in popularity throughout the 1990s. While arcade-style video game units have never completely died out, they generally remain as a novelty item. Personal Computer video games have also waned in sales in the 2000s but remain an important factor in many gaming genres, prominently in Role-Playing Games, Massively-Multi-Player Role-Playing Games, Simulations, and some First-Person Shooter games. As the dominant platform in video games sales continues to be the home-use console games, the balance of this historical account will now focus on these console video game platforms. With recent online-oriented massively-multiplayer games having favored the PC, it is possible that this platform regains a equal footing as the Eight-generation consoles begin to come to market.

\section{A History of the Generations of Video Game Consoles}

The earliest video game device for home use was developed by Ralph Baer in 1968 and was eventually licensed and released by Magnavox in 1972 (Novak, 2008). This system was called the Magnavox Odyssey and popularized the use of cartridges as the means of distributing games that persisted for 20 years or so (Baer, 2005). During its years of production, this system sold well in North America and Europe, achieving 2 million units in sales (Baer, 2005).

\section{First Generation}

The success of the Magnavox system understandably brought other players into the market and further developed the concept of utilizing Read-Only Memory (ROM) cartridges as a means of distributing games. Principle players in the market at this time were Atari with the 8-bit graphics Atari 2600 system, Mattel's Intellivision system with 16-bit graphics, and Coleco's ColecoVision which did not impact the market as significantly. It was this Second Generation of video game consoles that came to define the marketplace and develop the concept of a market for video games to be played at home. What typified this era was that games played at home were similar to, and often replication/emulations of, the games that were popular in video game arcades. Another concept that has stayed with the video game market that arose from this period is that of the third-party software developer of video games. Activision was among the first companies to develop for consoles that was not actually a manufacturer of the console (Anger, 2009). While this second generation of video game consoles fostered the beginnings of what we now call the video game market, the home video game console market was generating a revenue of $\$ 3.8$ billion in 1982, which was not quite half of what the coin-operated video game arcade market was generating at $\$ 8$ billion (Rogers \& Larsen, 1984).

\section{Second Generation}

Throughout the 1980s, what we now recognize as 'the video game industry' began to take shape. Several publishers and developers came and went during this period and some, like Electronic Arts, have persisted to this day. Such a wide variety of games were developed that they began to develop genre categorizations in much the same manner that both books and movies are categorized. Furthermore, although gaming consoles were responsible for growth in a video games market, interest in gaming also spurned on growth in the utility and versatility of home personal computers. Many personal computer icons of this era were also mediums for video game play - the Sinclair ZX series, the Commodore 64 and Amiga, the Atari ST, the Apple II and Macintosh, and the IBM PC and its clones. Today, both the PC and the Macintosh live on as the dominant personal computing and gaming platforms 
from that era (Novak, 2008). It was also during this era that the earliest forms of online gaming took root as gamers used modems attached to their home computers to reach dial-up bulletin board systems and others used services such as America Online and Prodigy to access the nascent infrastructure of the Internet. Another innovation from this same era was the advent of hand-held LED and LCD games. Many of these early hand-held games were quite primitive by today's standards and represented nothing more than a few blinking colored-LEDs.

\section{Third Generation}

By the mid-to-late 1980s, a significant change in the video game landscape was the arrival of the Japanese manufacturers and publishers. Nintendo released an 8-bit console called the Famicon/Nintendo Entertainment System (NES), which was a shift toward the physical and interface characteristics that came to dominate later generations of video game consoles. In general, the NES dominated this generation of video game consoles and brought about game titles like The Legend of Zelda, Dragon Quest, and Final Fantasy that persist to this day. As the 1990s arose, many significant innovations greatly affected the video game market and have shaped what we now know as the video game industry. As console power increased to 16-bit and 32-bit graphics, many arcade games were seen as passé; it was now possible to play better games in the home. Additionally, devices such as Nintendo's GameBoy, made mobile video game play possible. For a majority of the decade, video graphics were handled by the Central Processing Unit (CPU), where a separate processor for graphics acceleration rose to prominence toward the latter years of the decade. With the release of Microsoft's Windows 95 operating system and the continued decrease in the price of home personal computers, games for the PC and Mac gained significant popularity in the late 1990s, such that PC gaming was on par with console gaming. This was to be the last era where this fact would remain true.

\section{Fourth Generation}

The fourth generation of consoles is represented by the decade of the 1990s and was nearly and entirely dominated by Japanese manufacturers, such as Nintendo (with the Super NES) and Sega (with the Genesis). Most CPU processors were now 16-bit which allowed an increase in the quality of graphics and sound. Additionally, Moore's Law would provide a steady increase in the power of consoles with a concomitant reduction in the price of this power (Schaller, 1997). Another important change during this era was a shift toward using optical compact discs for the delivery of ROM content rather than via cartridges.

\section{Fifth Generation}

At the close of the 1990s and into the $21^{\text {st }}$ Century, console gaming caught up to and surpassed PC gaming in terms of sales. Additionally, a new player emerged into the market when Sony introduced their very successful PlayStation console. During the early portion of this era, in the mid-to-late 1990s, the Super NES and the PlayStation were the dominant platforms. Nintendo did respond by upping the ante with a 64-bit system (the Nintendo 64) and move the bar forward with this system. Despite the competition, the clearly dominant player in the video game console market at the turn of the $21^{\text {st }}$ Century was Sony. Also at this time, 3D-accelerated graphics became the norm in both PC and console gaming and this would remain the case until the present day.

\section{Sixth Generation}

At the onset of the $21^{\text {st }}$ Century, with Sony being the player to beat, the once-dominant Sega and Nintendo had fallen behind. Sega's response was a 128-bit console called the Dreamcast, which had built-in support for online play with an onboard modem. While the Dreamcast did stir the market initially, Sony's PlayStation 2 quickly unseated the Dreamcast and marked the end of Sega's participation in the hardware market. Nintendo also responded with the GameCube, which was their first optical disk-oriented device. The GameCube did not do as well in the market due to a lack of third-party game development support and other ill perceptions. By 2001, the video game console market was upset by another surprise new entrant - Microsoft with their Xbox system. What was remarkable about this system as that, internally, the hardware was more-or-less specified using PC orientation. In this sense, the Xbox was essentially a specialized gaming PC. As was the case with the Sonic the Hedgehog game title being synonymous with Sega Genesis system a decade earlier, Halo became a title synonymous with the Xbox and heralded and solidified Microsoft's position in the video game console market. 
Innovations of this time were strong advances in the quality and fidelity of the graphics output of the video game console devices and the widespread increase in the number of third-party game developers and the increased quality of their work. It was during this era that the big-budget game titles were beginning to be produced by equally high-stature development houses, such as Rockstar Games, Electronic Arts, and Bungie. Additionally, it became requisite that these games, and the consoles which hosted them, have an online component to them such that players could contest each other utilizing connections to the Internet. Microsoft developed a for-pay Xbox Live network, while Sony and Nintendo developed free networks. Player human-interaction devices also matured and diversified during this era where steering-wheels, joysticks, stepping pads (for dance movements) and musical instruments became alternative controllers for gaming titles like Dance Revolution, Guitar Hero, and Grand Turismo. While the PC had declined, many games returned to the PC and to hand-held devices in search of casual games that required less time investment and overall effort to play. The PC saw games like Myst and The Sims, and online and mobile casual games were also popularized by titles from Zynga Games, such as Mafia Wars and Farmville, as they tied into social networking websites, such as Myspace and Facebook.

\section{Seventh Generation}

The data used for the purposes of this study focus on the current, and quite mature, generation of video game consoles, known as the seventh generation. This generation is characterized by many innovations and diversification of game play. Dominant console platforms of this era are Microsoft's Xbox 360, Sony's PlayStation 3 , and the prominent and dominant return of Nintendo with their Wii system, which featured many innovations and is considered to have kicked off this current generation. The sales data show that Wii has dominated this generation since its introduction in 2006. While Microsoft did release the Xbox 360 in late 2005, the Wii has defined this era and the authors have elected to focus on sales data from the period spanning 2006 until mid 2011.

The innovations during this era are manifold and have moved video gaming to a new phase in many respects. Online gaming is now the norm and each major console - Microsoft's Xbox 360, Sony's PlayStation 3, and Nintendo's Wii - each provides means to access to online resources and players and each features their own network and online store. It has also become increasingly common to use seventh-generation game consoles as more than just a means of playing games: Sony's PlayStation 3 console is also a Blu-Ray Disc player and each manufacturer has created devices that can interact with other multi-media devices in the home. Thus, by the end of the first decade of the $21^{\text {st }}$ century, the video game console became the centerpiece of home entertainment and theater systems that easily rival what was available in many movie theaters from a decade or so earlier.

Another characteristic of this era was the advance of mobile gaming due to the extreme convergence of computing power, telecommunications, personal data devices, location sensors, and mobile gaming platforms. Smart Phones, like the iPhone and Android-capable devices, and Tablets like Apple's iPad, now comingle with Sony's PlayStation Portable and Nintendo's DS for the attention of video-gamers. Many gamers prefer the casual game-play of mobile games and this segment can be seen prominently in the game sales data. Additionally, many of these devices utilize touch-screen interfaces, which nearly remove all intermediaries between the gamer and the game.

The human interface to games during this era was also a striking innovation and an important reason why games for Nintendo's Wii system feature so prominently in the charts. What attracted so many to the Wii was that interaction with many of the games required body motion and movement. The Wii's controllers used accelerometers to detect body and limb motion and used this as a form of player input into the game. The attraction of this mode of human-computer interaction was so great that Wii titles, like Wii Sports, pulled ahead of the rest of the pack in a staggering manner. Microsoft (Kinect) and Sony (Move) have responded to this phenomenon, with Microsoft's Kinect device reinvigorating the now-aging Xbox 360. Whereas the Wii remote (Wii-mote) relies on accelerometers, the Kinect uses infrared (IR), sound, and other visual sensors to detect changes in heat in the background image seen by the device. This trend toward the incorporation of movement has also continued a trend toward casual games dominating the market. This is remarkable as the budget for these games is much lower than what is required for many top-selling games, such as Modern Warfare 3. Many top-selling First-Person Shooter (FPS) games required massive investment in developing top-quality 2D and 3D art, mastering the latest 3D Application Programming Interfaces from the hardware manufacturers and mastering the latest programming 
techniques for performance optimization. A casual gaming title requires nowhere near the same level of investment, and yet the sales data will show that casual games can sell quite well. As of 2011, the end of this era is nearing, a most recent innovation, which will likely move gaming consoles into the next era, is the incorporation of newer 3D technologies which enables most modern displays/televisions to show output in 3D using special glasses.

The seventh-generation consoles represent two form-factors, or modes - console systems and hand-held systems. Typically, the same manufacturers are involved in both form-factors. The current generation of game consoles began when Microsoft launched the Xbox 360 on November 22, 2005 - in time for the holiday shopping season. Within a year's time, Sony joined the seventh generation with the PlayStation 3 - on November 11, 2006, and Nintendo followed closely behind with the game-changing Wii - released on November 16, 2006. Each of these consoles had settled on a hardware architecture which used 128-bit data. However, each console has important architectural differences which are outlined in Table 1. This generation also saw the advent of hand-held devices, such as the Nintendo DS - released on November 21, 2004 - and the Sony's PlayStation Portable - released on December 12, 2004.

\section{Comparing the Home Consoles}

While the data will show the hand-held market to be an important factor in sales, there is little doubt that consoles continue to dominate sales overall. This section will characterize the three principle consoles as they have evolved throughout their lifetime. It is important to note that some of the features, capabilities and power of these devices have changed over their lifetime. Table 1 offers a comparison of seventh-generation consoles.

What stands out in Table 1 is that, technologically, the PlayStation 3 and the Xbox 360 are fairly matched in terms of the capabilities of their hardware. It is somewhat odd that the PlayStation 3 does not outsell the Xbox 360 in that Microsoft is known for charging more for additional accessories and peripherals as well as charging for the Xbox Live service. Also of note is that while the Wii outsells the others, it features the weakest hardware of all the consoles. The success of the Wii is largely centered on its promotion of social-oriented gaming due to the requirement that players move their bodies in order to work with the accelerometers in the Wii-mote for the bestselling titles. Also of note is that Wii Sports is a title that is bundled with the Wii system. This might explain the high sales figure for this title compared to others. Nintendo has used this tactic 15 years earlier when Sonic the Hedgehog was bundled with the NES and Super NES systems in the late 1980s and early 1990s.

Table 1: Comparing the Seventh-Generation Consoles

\begin{tabular}{|c|c|c|c|}
\hline Factor & Microsoft Xbox 360 & Sony PlayStation 3 & Nintendo Wii \\
\hline $\begin{array}{l}\text { North American Release } \\
\text { Data }\end{array}$ & November $22^{\text {nd }}, 2005$ & November $11^{\text {th }}, 2006$ & November $19^{\text {th }}, 2006$ \\
\hline Central Processing Unit & $\begin{array}{l}\text { 3.2 GHz IBM PowerPC tri- } \\
\text { core "Xenon" }\end{array}$ & $\begin{array}{c}3.2 \mathrm{GHz} \text { Cell Broadband } \\
\text { Engine }\end{array}$ & $729 \mathrm{MHz}$ IBM PowerPC \\
\hline Graphics Processing Unit & $55 \mathrm{MHz}$ ATI "Xenos” & $\begin{array}{c}550 \mathrm{MHz} \text { NVidia G70-based } \\
\text { RSX }\end{array}$ & 243 MHz ATI "Hollywood" \\
\hline Memory & $512 \mathrm{MB}$ GDDR3 at $700 \mathrm{MHz}$ & $\begin{array}{c}256 \mathrm{MB} \text { XDR at } 3.2 \mathrm{GHz} \\
256 \mathrm{MB} \text { GDDR3 at } 700 \mathrm{MHz}\end{array}$ & $\begin{array}{c}24 \mathrm{MB} \text { internal graphics } \\
\text { memory } \\
64 \mathrm{MB} \text { external GDD3 }\end{array}$ \\
\hline Best-selling game & $\begin{array}{l}\text { Call of Duty: Black Ops } \\
\text { (\$13.2 million) }\end{array}$ & $\begin{array}{l}\text { Call of Duty: Black Ops } \\
\text { (\$11.1 million) }\end{array}$ & Wii Sports (\$79.3 million) \\
\hline Milestone Titles & $\begin{array}{l}\text { Bioshock, Gears of War, } \\
\text { Grand Theft Auto, Halo } 3\end{array}$ & $\begin{array}{c}\text { LittleBigPlanet, Uncharted 2: } \\
\text { Among Thieves }\end{array}$ & $\begin{array}{c}\text { Wii Sports, Super Mario } \\
\text { Galaxy, Super Smash } \\
\text { Brothers Brawl }\end{array}$ \\
\hline Online Service & Xbox Live (paid subscription) & PlayStation Network (free) & WiiConnect (free) \\
\hline Consumer Development & XNA Game Studio (Free) & Free development RSX tools & WiiWare (for pay) \\
\hline Max Resolution & $1080 \mathrm{p}, \mathrm{i}$ & $1080 \mathrm{p}, \mathrm{i}$ & $576 \mathrm{i}, 480 \mathrm{p}$ \\
\hline $\begin{array}{l}\text { Initial Storage Lowest } \\
\text { Capacity }\end{array}$ & 20GB & 20GB & $512 \mathrm{MB}$ \\
\hline Highest Storage Capacity & 250GB & $320 \mathrm{~GB}$ & 32GB with SD card \\
\hline Worldwide units sold & 61.5 million & 58.2 million & 92.3 million \\
\hline
\end{tabular}




\section{Comparing the Hand-Held Systems}

The sales data show that hand-held systems are a significant portion of the market for seventh generation devices. There are really only two players in this market, if Smart Phones are excluded - the Nintendo DS and the Sony PlayStation Portable. The sales data show that, even as of 2011, games sold as apps for Smart Phones are not yet a factor. This is likely due to how sales data is categorized for games as games are thought to run primarily on dedicated devices or on PCs. In the future, sales aggregation and analysis companies, such as NPD and VGChartz, will continue to integrate sales data for game apps (applications) sold for use on Smart Phones and Tablets. Table 2 lists the characteristics and features of the hand-held gaming systems in the seventh generation of game devices. Looking at Table 2, hand-helds have lower unit sales than consoles, but the sales data show that some hand-held titles have healthy sales that rival that of console titles. It is evident that the capabilities of the hand-helds are inferior to those of the consoles which is to be expected of a portable device. As is the case in consoles, the Sony device leads the group technologically, but the lower-tech Nintendo device outsells the Sony device.

Table 2: Comparing the Seventh-Generation Hand-Helds

\begin{tabular}{|l|c|c|}
\hline \multicolumn{1}{|c|}{ Factor } & Nintendo DS & Sony PlayStation Portable \\
\hline North American Release Date & November 21, 2004 & December 12, 2004 \\
\hline Media & $\begin{array}{c}\text { DS Game Card, GameBoy Advance } \\
\text { cartridge, SD(HC) card }\end{array}$ & $\begin{array}{c}\text { Universal Media Disc, Memory Stick } \\
\text { Micro, Flash Memory }\end{array}$ \\
\hline Memory & $67 \mathrm{MHz}$ ARM - 133 MHz ARM & R4000 up to 333MHz \\
\hline Best-Selling Games & $4-16 \mathrm{MB} \mathrm{SRAM}$ & $32-64 \mathrm{MB}$ EDRAM \\
\hline Online Service & Nintendogs and New Super Mario \\
\hline Worldwide units sold & Brothers & $\begin{array}{c}\text { Monster Hunter Portable and Grand Theft } \\
\text { Auto: Liberty Stories }\end{array}$ \\
\hline
\end{tabular}

\section{DATA AND MODEL}

As we have demonstrated the centrality of platforms in the console-based home video game market, we now consider our central research interests. Primarily, we are interested to know if there is a difference in video game sales by different platform classifications. This section proposes a model to compare the annual global video game sales by platform for the years 2006 through 2011. The period closely mirrors the lifespan of a generation of home video game console hardware. The data consist of the top 100 ranking in annual sales by the video game platforms Nintendo DS (DS), Nintendo GameCube (GC), Personal Computer (PC), Sony PlayStation 2 (PS2), Sony PlayStation 3 (PS3), Sony PlayStation Portable (PSP), Nintendo Wii (Wii), and Microsoft Xbox 360 (X360). Ten different platforms were considered in the sample, but two (Nintendo Game Boy Advanced and Microsoft Xbox) have been eliminated for not having five or more games placing in the sample of annual top 100 in sales. This is so as these platforms were characteristic of a previous generation of video game consoles and were largely being phased out at the start of the study period. The primary data source is the VGChartz website, which offers extensive data relating to annual sales of video games by platform.

The statistical methodology incorporates a nonparametric approach to comparing the video game sales revenue across gaming platforms. A traditional event study is not the most efficient approach for this specific research design because the research periods require a long-time horizon instead of the narrow window associated with an event study. The lack of linearity in the data, resulting from the substantial increase in sales moving from sixth to seventh generation consoles, reduces the effectiveness of employing traditional regression analysis. The nonparametric Kruskal-Wallis test that is employed offers the most powerful test statistic in a completely randomized design without assuming a normal distribution. The Kruskal-Wallis test is sensitive to differences among means in the $k$ populations and is extremely useful when the alternative hypothesis is that the $k$ populations do not have identical means. The null hypothesis is that the $k$ video game sales in the different platforms come from an identical distribution function. For a complete description of the Kruskal-Wallis test, see Conover (1980). The specific equations used in the calculations are as follows:

$\mathrm{N}=\sum_{\mathrm{i}} \mathrm{n}_{\mathrm{i}}$ with $\mathrm{i}=1$ to $\mathrm{k}$

$\mathrm{R}_{\mathrm{i}}=\sum_{\mathrm{j}} \mathrm{R}\left(\mathrm{X}_{\mathrm{ij}}\right)$ with $\mathrm{j}=1$ to $\mathrm{n}_{\mathrm{i}}$ 
$\mathrm{R}_{\mathrm{j}}=\sum_{\mathrm{i}} \mathrm{O}_{\mathrm{ij}} \mathrm{R}_{\mathrm{i}}$ with $\mathrm{i}=1$ to $\mathrm{c}$

$\mathrm{S}^{2}=[1 /(\mathrm{N}-1)]\left[\sum_{\mathrm{i}} \mathrm{t}_{\mathrm{i}} \mathrm{R}_{\mathrm{i}}^{2}-\mathrm{N}(\mathrm{N}+1)^{2} / 4\right]$ with $\mathrm{i}=1$ to $\mathrm{c}$

$\mathrm{T}=\left(1 / \mathrm{S}^{2}\right)\left[\sum_{\mathrm{i}}\left(\mathrm{R}_{\mathrm{i}}^{2} / \mathrm{n}_{\mathrm{i}}\right)-\mathrm{N}(\mathrm{N}+1)^{2} / 4\right]$ with $\mathrm{i}=1$ to $\mathrm{k}$

$\left|\left(\mathrm{R}_{\mathrm{i}} / \mathrm{n}_{\mathrm{i}}\right)-\left(\mathrm{R}_{\mathrm{j}} / \mathrm{n}_{\mathrm{j}}\right)\right|>\mathrm{t}_{1-\mathrm{a} / 2}\left[\mathrm{~S}^{2}(\mathrm{~N}-1-\mathrm{T}) /(\mathrm{N}-\mathrm{k})\right]^{1 / 2}\left[\left(1 / \mathrm{n}_{\mathrm{i}}\right)+\left(1 / \mathrm{n}_{\mathrm{j}}\right)\right]^{1 / 2}$

In the equations above, $R$ is the variable rank and $N$ is the total number of observations. The first three equations find average ranks. Equation (4) calculates the sample variance while equation (5) represents the test statistic. If, and only if, the decision is to reject the null hypothesis, equation (6) determines multiple comparisons of video game sales across the various gaming platforms.

\section{RESULTS}

Table 3 offers summary global video game sales statistics for the eight video game platforms in the research cohort. The Nintendo Wii offers the most impressive numbers with average sales of $\$ 8.37$ million per video game in the research sample. In fact, the Wii platform leads the way with the top nine video games in sales. The top nine Nintendo Wii games all have gross global sales over \$25 million, which includes 2011 sales of Wii Sports topping the list at $\$ 71$ million. Fifteen total Nintendo Wii games exceed the $\$ 20$ million mark in annual global sales revenue. Nintendo DS offers seven games that exceed \$20 million in annual sales from the Super Mario Kart, Nintendogs, and Super Mario Brothers series of games. Xbox 360 offers 13 games with annual global sales over \$7.5 million, 10 of which are derived from the Call of Duty and Halo series of games. Five PS 2 and five PS 3 games from the Grand Theft Auto, Call of Duty, and Gran Turismo series offer global annual sales in excess of $\$ 7.5$ million. Seven of the eight video game platforms average over $\$ 1.7$ million in annual global sales per game. Only the GameCube platform games fail to have a single game title cross the $\$ 2$ million sales threshold and do not average at least $\$ 1$ million in annual global sales revenue.

Table 3: Summary Statistics for Annual Global Video Game Sales by Platform (2006-2011)

\begin{tabular}{|l|c|c|c|c|c|}
\hline \multicolumn{1}{|c|}{ Platform } & Mean & Median & Standard Deviation & Minimum & Maximum \\
\hline DS & $5,063,956$ & $2,401,315$ & $6,034,259$ & 346,675 & $25,624,345$ \\
\hline GC & 717,646 & 674,495 & 224,008 & 513,684 & $1,007,910$ \\
\hline PC & $2,101,539$ & $1,917,124$ & $1,233,574$ & 342,013 & $4,297,421$ \\
\hline PS2 & $2,574,883$ & $1,212,023$ & $3,753,261$ & 526,681 & $17,748,855$ \\
\hline PS3 & $2,447,583$ & $1,775,276$ & $1,982,612$ & 329,024 & $10,124,463$ \\
\hline PSP & $1,760,524$ & $1,465,685$ & $1,280,831$ & 331,955 & $4,556,375$ \\
\hline Wii & $8,379,519$ & $3,305,162$ & $13,322,137$ & 474,339 & $76,502,625$ \\
\hline X360 & $1,770,002$ & $1,890,329$ & $2,716,430$ & 323,183 & $12,570,973$ \\
\hline
\end{tabular}

The nonparametric empirical approach yields a T-value of 26.53 (p-value $=.0001$ ), indicating a significant difference in annual video game sales across the eight platforms in the study. Table 4 shows average rank order value of annual video game sales in the global market derived from a Kruskal-Wallis nonparametric methodology for each platform across the six years of this study. The average rank of sales column is the value of the equation (5) test statistic and p-value for each company, which determines if there is a statistical difference across platforms. Assuming an alpha level of .05, the empirical results from equation 6 identifies five statistically different tiers of sales categories across the eight platform categories. Asterisks $(*)$ signify differences in average rank values as follows:

(1) $\quad * * * * *$ Indicates period with highest statistically significant sales derived from equation 6.

(2) $\quad * * * *$ Indicates period with second highest statistically significant sales derived from equation 6.

(3) $\quad * * *$ Indicates period with third highest statistically significant sales derived from equation 6.

(4) ** Indicates period with fourth highest statistically significant sales derived from equation 6.

(5) * Indicates period with the lowest statistically significant sales derived from equation 6.

(6) Some periods do not have a return that is statistically significant from an alternative period. 
Table 4: Average Rank Order Value of Global Video Game Sales (2006-2011)

\begin{tabular}{|l|c|c|}
\hline \multicolumn{1}{|c|}{ Platform } & Number of Top 100 Titles & Average Rank Value of Sales \\
\hline DS & 136 & $270.0^{* * * *}$ \\
\hline GC & 4 & $529.8^{*}$ \\
\hline PC & 14 & $327.4^{* * *}$ \\
\hline PS2 & 56 & $378.3^{* *}$ \\
\hline PS3 & 104 & $323.2^{* * *}$ \\
\hline PSP & 33 & $382.4^{* *}$ \\
\hline Wii & 104 & $226.9^{* * * * *}$ \\
\hline X360 & 164 & $314.1^{* * *}$ \\
\hline
\end{tabular}

The most interesting observation is the dominance of two of the Nintendo platforms. The Nintendo Wii and the hand-held Nintendo DS are the top two tiers of sales with average rankings of 226.9 and 270, respectively. The interesting thing about the Nintendo platforms is that the technology employed is not as robust as the technology of Sony and Microsoft competitors. Tables 1 and 2 both demonstrate the technological supremacy of the alternative platforms. Clearly, technological capacity is not the primary factor influencing video game sales. The Nintendo platforms have used first-mover advantages in both hand-held gaming and human movement consoles. Although Sony followed Nintendo with superior hand-held and human movement consoles, the first-mover advantage is more important than the technological sophistication for the majority of casual gamers. The body and limb motion of the Wii opens markets beyond the domain of traditional children and young men as gamers. The Wii has been positively marketed and sold as a fitness tool to families as a modern replacement for board games and a vehicle for multi-generational interaction. In addition, the Nintendo platforms, like the Wii, are sold at an entry price that is substantially cheaper than the competitive alternatives. An interesting challenge for Nintendo DS in the future will be maintaining sales in light of the continuing rise of smartphones, tablets, and other alternative threats.

Microsoft Xbox 360, Sony PS 3, and games for the personal computer share the third tier of sales. The Xbox 360 is the second video game console produced by Microsoft and the successor to the Xbox. Xbox 360 was considered, at the time of release, revolutionary and superior to the Sony PlayStation 2 and the Nintendo GameCube. The Xbox 360 gained significant market share as the first-mover into the seventh generation of consoles. The 2007 Game Critics Awards honored the Xbox 360 platform with 38 Nominations and 11 Wins (Game Critics, 2007). By March 2008, the Xbox 360 had reached a software attach rate of 7.5 games per console while its competitors were 3.8 for PS3 and 3.5 for Wii (Davis, 2008). To date, over 77 million Xbox 360 consoles have been sold worldwide. Call of Duty, Halo, Grand Theft Auto, Gears of War, Guitar Hero, and Kinect Adventures are the dominant games for the Xbox 360 platform. Despite the observation that the Nintendo Wii is the leader in video game sales, the technological superiority of the Xbox 360 and Sony PlayStation 3 is not ignored by ardent gamers. Microsoft has developed a solid platform with many dedicated gamers. The much anticipated 2013 release of the new Xbox One platform will determine if Microsoft can move to the top of the gaming platform competition.

The personal computer platform falls into the third tier of video game sales. While a gaming-oriented personal computer platform will offers graphical capabilities that far exceed those of the Nintendo, Microsoft, and Sony consoles, hardware prices for these machines are typically 2-3 times (and as much as 10 times) the hardware price of a console. Additionally, the PC does not offer the portability of the Nintendo DS and Sony PSP hand-held devices. Despite these limitations, StarCraft and World of Warcraft series of games combined for six titles with annual global sales earning over \$2 million for personal computer platform. This means that the PC will continue to hold sway in certain niche categories and for those with a taste for high-end hardware. The data show that the international market, in particular in Europe, continues to value the PC as a gaming platform. An interesting focus point for the future will be the battle for the mobile hand-held market. The iPhone and other mobile devices are making significant inroads into the hand-held market. The relative decline in the mobile platform for Nintendo and Sony could indirectly help the personal computer platform maintain a low cost and/or high-end alternative niche in the gaming industry.

Three Sony platforms are in the third and fourth tier rankings for video game sales in the research cohort. The specific platforms are PlayStation 3 in the third tier of sales with an average rank of 323.2 followed by PlayStation 2 and PlayStation Portable placing in the fourth tier of global sales revenue. It is worth nothing that the PlayStation 2 is the only Sony product in the first few years of the research sample but PlayStation 3 dominates the 
last few years for gamers that prefer the Sony platform. There was a time before the year 2006 when the Sony PlayStation and the Sony PlayStation 2 held the unique position of being the top console for both relative quality and total sales. Sony waited for a year after the Xbox 360 launched to release their PlayStation 3. The Xbox 360 gained a significant amount of market share over the Sony platform as a first-mover into the high-end seventh generation High-definition (HD) console. The PlayStation 3 late entry into the seventh generation competition gave Sony the superior console but the technological advancement was not been significant enough to regain the top spot in the console platform. Sony will play an important role in the future of the video game business. Superior technology and a strong entertainment division, that includes the ability to cross into the movie industry, puts Sony in a prime position as the gaming industry approaches the eighth generation of consoles. A key strategy for the future of the Sony platform is to roll out the PlayStation 4 around the same time their competitors' consoles. The PSP platform has seven titles in the research cohort with over \$3 million in annual global sales but the future of the hand-held platform appears to be moving toward smartphones and other robust hand-held devices (e.g., iPad and various tablet technologies).

The fifth tier of video game sales in the sample cohort is the Nintendo GameCube. The Nintendo GameCube is a sixth generation video game console first released by Nintendo in 2001. It was the successor to the Nintendo 64. The GameCube sold over 21 million units worldwide before the Nintendo Wii was released in November 2007 as the seventh generation replacement. In contrast with the GameCube's contemporary competitors, Sony's PlayStation 2, Sega's Dreamcast and Microsoft's Xbox, the GameCube uses mini DVD-based discs instead of full-size DVDs. The GameCube does not have the DVD-Video playback or the audio CD playback functionality of other consoles that use full-size optical discs. The rise of the Nintendo Wii as the successor to the GameCube illustrates the ability of platforms to find a new competitive success as the gaming platforms move from one generation to next.

\section{CONCLUSION}

The purpose of this research is to compare global video game sales by gaming platform for the years 2006 through 2011. The statistical methodology incorporates a nonparametric Kruskal-Wallis test to compare the eight gaming platforms in the research cohort. Our literature review revealed that the home video game market is very platform-oriented and our empirical work has sought to clarify this. The results of this study show clear differences in sales by platform along brand lines. Nintendo is clearly the gaming leader during the research timeframe with Wii as the dominant console and DS the leading hand-held platforms. Nintendo had fallen behind Sony in the timeframe preceding the research sample but the first-mover introduction of the Wii human interface body motion and movement has propelled Nintendo to the top spot. The attraction of this mode of human-computer interaction was so great that Wii titles, like Wii Sports, pull ahead of the rest of the pack in a staggering manner. We also find that Wii Sports did well as Nintendo adopted an important vertical integration strategy. The third tier of sales is the domain of Microsoft with the Xbox 360 platform, Sony Playstation 3, and personal computer games. The Xbox 360 used a 12-month release date head start to gain market share in the seventh generation High-definition (HD) console competition with Sony's PlayStation 3 and Nintendo's Wii. One explanation for Sony's third tier placing, despite leading technology, is their late arrival to several key advancements like HD, motion sensor, and hand-held gaming. The clear gains from first-mover innovation make the race to the eighth generation of consoles a very important strategic position for Nintendo, Microsoft, and Sony. The fourth tier grouping of sales includes the sixth generation PlayStation 2 and hand-held PlayStation Portable. The sixth generation Nintendo GameCube rounds out the field with placing in the fifth tier of global sales by platform.

Academic research into the video game industry is an important and emerging area. Several potential advancements and extensions of this work are viable future research topics. One limitation of the study is the lack of a robust empirical model to investigate the determinants of video game sales. Future research should explore determinants of video game sales revenue via a multiple regression model controlling for platform, genre, ESRB rating, publisher, critical reviews, and other potential determinants.

A second opportunity for future research is to open an inquiry into the mechanics and nature of the video game sales market and industry. A few emerging phenomena have us convinced that this, the most successful of video game console generations, may also herald the end of an era. Principal among these new phenomena is the 
mobile device industry and the propensity for entertainment content to be increasingly delivered via the Internet. Whereas Sony and Nintendo enjoyed great success with their hand-held gaming devices, it is likely that Smart Phones and tablets, targeting the iOS platforms and the Android platforms, will dominate moving forward. In both cases, while the platform paradigm remains dominant, the delivery mechanisms are presently (and moving forward) aimed at content delivery through the network. Moreover, the return of data centralization, in its current manifestation in "the cloud", means that content is available on a device wherever the player is. While the portability of game consoles means that they will likely have a place in the video game sales platform scene, mobile devices, and even the PC, are again leveling the field. For instance, online sales and distribution systems for the PC, such as Steam and Impulse, have brought on resurgence in the PC platform, particularly in the strategy, indie games, casual games, and simulation genres to which the PC is well-suited.

A third avenue for future research is to explore the potential for mergers and acquisitions in the video game industry. As hardware generations have shifted in the past, we have seen players enter, leave, or even re-enter the marketplace. The timing is ripe for a new entrant into the market who understands both hardware and online delivery; such a player could be Apple. Furthermore, if a company like Apple entered the market, they will likely subsume, or eliminate, one of the extant players. As well as Nintendo did in the seventh generation, there is competitive advantage left in the human-computer kinesics market as, in many respects, Microsoft's Kinect is a superior device and a company like Apple has also pioneered in this area with the iPhone/iPad. While both Microsoft and Sony are poised to expand online delivery, the entire content-delivery ecosystem, as it currently stands, centers around the increasingly-quaint concept of obtaining the software on a physical medium and situating and marketing that physical manifestation in a brick-and-mortar store.

\section{AUTHOR INFORMATION}

Dr. Jeffry Babb is the Terry Professor of Business and instructor of computer information systems at West Texas A\&M University in Canyon, Texas. Dr. Babb earned a doctorate degree in computer information systems from Virginia Commonwealth University. E-mail: jbabb@wtamu.edu

Dr. Neil Terry is dean and professor of economics at West Texas A\&M University in Canyon, Texas. Dr. Terry earned a doctorate degree in economics from Texas Tech University. E-mail: nterry@wtamu.edu (Corresponding author)

Mr. Kareem Dana is an instructor of computer information systems at West Texas A\&M University in Canyon, Texas. Mr. Dana earned an M.S. degree in computer science from Duke University. E-mail: kdana@ wtamu.edu

\section{REFERENCES}

1. Aldrich, C. (2009). The Complete Guide to Simulations and Serious Games: How the Most Valuable Content Will be Created in the Age Beyond Gutenberg to Google. San Francisco: Pfieffer.

2. Anderson, J. (1983, Spring). Who Really Invented the Video Game? Creative Computing Video and Arcade Games, $1,1$.

3. Anger, M. (2009). Speak, Atari. Retrieved September 15th, 2011, from http://www.slate.com/id/2213124/pagenum/all/\#p2

4. $\quad$ Arakji, R. Y., \& Lang, K. R. (2007). Digital Consumer Networks and Producer-Consumer Collaboration: Innovation and Product Development in the Video Game Industry. Journal of Management Information Systems, 24(2), 195-219.

5. Babb, J. \& Terry, N. (2013). Comparing Video Game Sales by Gaming Platform. Southwestern Economic Review, 40(1), 25-46.

6. Baer, R. H. (2005). Videogames: In the Beginning. New Jersey: Rolenta Press.

7. Benthem, J. (2011). Logic Games: From Tools to Models of Interaction. In J. Benthem, A. Gupta \& R. Parikh (Eds.), Proof, Computation and Agency (Vol. 352, pp. 183-216). Netherlands: Springer.

8. Bhattacharjee, S., Gopal, R. D., \& Sanders, L. G. (2003). Digital Music and Online Sharing: Software Piracy 2.0? Communications of the ACM, 46(7), 107-111. 
9. Bikhchandani, S., Hirshleifer, D., \& Welch, I. (1992). A Theory of Fads, Fashion, Custom, and Cultural Change as Informational Cascades. Journal of Political Economy, 100(5), 992-1026.

10. Binken, J., \& Stremersch, S. (2009). The Effect of Superstar Software on Hardware Sales in System Markets. Journal of Marketing Research, 73(2), 88-104.

11. Briscoe, B., Odlyzko, A., \& Tilly, B. (2006). Metcalfe's Law is Wrong - Communications Networks Increase in Value as they Add Members-but by How Much? IEEE Spectrum, 43(7), 34-39.

12. Chatfield, T. (2010). Fun Inc. Why Gaming with Dominate the 21st Century. New York: Pegasus Books.

13. Chiou, L. (2008). The timing of movie releases: Evidence from the home video industry. International Journal of Industrial Organization, 26(5), 1059-1073.

14. Claussen, J. (2011). Vertical Integration Under Uncertainty - Evidence From The PC Gaming Industry. Paper presented at the Dime-Druid Academy Winter Conference 2011.

15. Clements, M. T., \& Ohashi, H. (2004). Indirect Network Effects and the Product Cycle: Video Games in the U.S., 1994-2002. Unpublished Working Paper. NET Institute.

16. Conover, W. (1980). Practical Nonparametric Statistics. New York: John Wiley \& Sons Publishing.

17. Davis, T. (2008). Xbox 360 Comes in 2nd for March Sales. The Bit Bag. 2008-04-17. Retrieved 2011-1202.

18. Deterding, S., Khaled, R., Nacke, L. E., \& Dixon, D. (2011). Gamification : Toward a Definition. Design. Paper presented at the Proceedings of the 2011 annual conference extended abstracts on Human factors in computing systems.

19. Deterding, S., Sicart, M., Nacke, L., O'Har, K., \& Dixona, D. (2011). Gamification. using game-design elements in non-gaming contexts. Paper presented at the Proceedings of the 2011 annual conference extended abstracts on Human factors in computing systems.

20. Game Critics Award (2007). Winners. Retrieved 12/02/2011, from http://GameCriticsAwards.com

21. Gallagher, S., \& Park, S. H. (2002). Innovation and Competition in Standard-Based Industries: A Historical Analysis of the U.S. Home Video Game Market. IEEE Transactions on Engineering Management, 49(1), 67-82.

22. Gil, R., \& Warzynski, F. (2010). Vertical Integration, Exclusivity and Game Sales Performance in the US Video Game Industry. Networks, Electronic Commerce, and Telecommunications Institute.

23. Graetz, J. M. (1981). The Origin of Spacewar. Creative Computing, 18.

24. Grant, C. (2010). Xbox by the Numbers: 20m Xbox Live users, 10m nongaming, 39m Xbox 360 consoles worldwide. Joystiq, 1.

25. Hsu, P. and Tsai C. (2012). Evaluating the Virtual Products for Online Games via the Grey Relational Analysis. International Journal of E-Adoption. 4(3), 39-47.

26. Johns, J. (2006). Video Games Production Networks: Value Capture, Power Relations and Embeddedness. Journal of Economic Geography, 6(2), 151-180.

27. Jones, C., Svejenova, S., \& Srandgaard, J. (2011). Misfits, Mavericks and Mainstreams: Drivers of Innovation in Creative Industries. Organization Studies, 32(3).

28. Katz, M. L., \& Shapiro, C. (1985). Network Externalities, Competition, and Compatibility. American Economic Review, 75(3), 424-440.

29. Katz, M. L., \& Shapiro, C. (1994). Systems Competition and Network Effects. The Journal of Economic Perspectives, 8(2), 93-115.

30. King, T. (2007). Does film criticism affect box office earnings? Evidence from movies released in the U.S. in 2003. Journal of Cultural Economics, 31, 171-186.

31. Landsman, V., \& Stremersch, S. (2011). Multihoming in Two-Sided Markets: An Empirical Inquiry in the Video Game Console Industry. Journal of Marketing, 75, 39-54.

32. Litman, B. (1983). Predicting success of theatrical movies: An empirical study. Journal of Popular Culture, 16 (spring), 159-175.

33. Liu, H. (2010). Dynamics of Pricing in the Video Game Console Market: Skimming or Penetration? Journal of Marketing Research, 47, 428-443.

34. Novak, J. (2008). Game Development Essentials (2nd ed.). Clifton Park, NY: Delmar Cengage.

35. Orland, K. (2013). Valve lets you pay for the beta with Steam 'Early Access' program. Ars Technica. Retrieved 06/01/2013, from http://arstechnica.com/gaming/2013/03/valve-lets-you-pay-for-the-beta-withsteam-early-access-program 
36. Parker, G. G., \& Alstyne, M. W. V. (2005). Two-Sided Network Effects: A Theory of Information Product Design. Management Science, 51(10), 1494-1504.

37. Poole, S. (2000). Trigger Happy. London: Fourth Estate.

38. Prieger, J. E., \& Hu, W.-M. (2006). An Empirical Analysis of Indirect Network Effects in the Home Video Game Market. Unpublished Working Paper. NET Institute.

39. Reeves, B., \& Read, J. L. (2009). Total Engagement: Using Games and Virtual Worlds to Change the Way People Work and Businesses Compete. Boston: Harvard Business School Press.

40. Ritchie, D. (2011). Yes, A Video Game Contributed to Unix Development. Retrieved September 15th, 2011, from http://people.fas.harvard.edu/ lib215/reference/history/spacetravel.html

41. Rochet, J.-C., \& Tirole, J. (2003). Platform Competition in Two-Sided Markets. Journal of the European Economic Association, 1(4), 990-1029.

42. Rochet, J.-C., \& Tirole, J. (2006). Two-Sided Markets: A Progress Report. The RAND Journal of Economics, 37(3), 645-667.

43. Rogers, E. M., \& Larsen, J. J. (1984). Silicon Valley Fever: Growth of High-Technology Culture. Charlottesville, VA: University of Virginia.

44. Schaller, R. R. (1997). Moore's Law: Past, Present, and Future. IEEE Spectrum, 34(6), 52-59.

45. Shankar, V., \& Bayus, B. L. (2003). Network Effects and Competition: An Empirical Analysis of the Home Video Game Industry. Strategic Management Journal, 24, 375-384.

46. Simeonov, S. (2006). Metcalfe's Law: more misunderstood than wrong? Retrieved November 25, 2011, from http://blog.simeonov.com/2006/07/26/metcalfes-law-more-misunderstood-than-wrong

47. Sliwinski, A. (2012). Call of Duty: Black Ops 2 Sales Reach $\$ 1$ billion in 15 days. Retrieved June 1, 2013, from http://www.joystiq.com/2012/12/05/call-of-duty-black-ops-2-1-billion

48. Strube, J., Schade, S., Schmidt, P., \& Buxmann, P. (2007). Simulating Indirect Network Effects in the Video Game Market. Paper presented at the Proceedings of the 40th Hawaii International Conference on System Sciences.

49. Stuart, K. (2011). Modern Warfare 3 Smashes Records: \$775m in Sales in Five Days. The Guardian.

50. Terry, N., Butler, M., \& De’Armond, D. A. (2005). The Determinants of Domestic Box Office Performance in the Motion Picture Industry. Southwest Economic Review, 32(1), 137-148.

51. Terry, N., Cooley, J., \& Zachary, M. (2010). The determinants of foreign box office revenue for English language movies. Journal of International Business and Cultural Studies, 2(1), 12.

52. Terry, N., King, R., \& Walker, J. J. (2010). The Determinants of Box Office Revenue for Horror Movies. Journal of Global Business Management, 6(2), 10.

53. Trispas, M. (2000). Adobe Systems, Inc. Cambridge: Harvard Business School.

54. Tschang, F. (2007). Balancing the Tensions Between Rationalization and Creativity in the Video Games Industry. Organization Science 18(6), 989-1005.

55. VGChartz. (2011). Video Game Sales. Retrieved 08/01/2011, from http://www.vgchartz.com

56. Wang, H. and Chin, A. (2011). Social Influence on Being a Pay User in Freemium-based Social Networks. 2011 IEEE International Conference on Advanced Information Networking and Applications, Singapore, March 22-25, 2011, 526-533.

57. Williams, D. (2002). Structure and Competition in the U.S. Home Video Game Industry. The International Journal on Media Management, 4(1), 41-54.

58. Wortley, D. (2013). Immersive Technology Strategies. Simulation \& Gaming, page 15.

59. Zackariasson, P., Styhre, A., \& Wilson, T. L. (2006). Phronesis and Creativity: Knowledge Work in Video Game Development. Creativity and Innovation Management, 15(4), 419-429.

60. Zhu, F., \& Iansiti, M. (2012). Entry into platform-based markets. Strategic Management Journal, 33, 88106. 